\title{
COMPRESSION OF THE HEAD, CAUSING TEMPORARY SIXTH NERVE PARALYSIS
}

\author{
BY \\ C. G. SCHURR \\ BRIGHTON
}

History.-On or about August 24, 1929, while on holiday in Belgium, D. H., aged 4 years, put her head through one of the openings of the steel trellis-work gate of the hotel lift. The lift descended, but automatically stopped, compressing the head between the occiput and the chin. The child was fixed in this position for about half a minute.

When she was released, the child's face was swollen, " black and blue," and she was unconscious. Her chin was cut.

She remained unconscious for 24 hours, and during this time there was frequent vomiting.

When consciousness returned, it was found that the left eye turned in. The swelling of the lace lasted for two days.

I did not see the child until a fortnight after the accident.

Clinical.-When examined on September 6, 1929, the condition found was as follows :-

There was a healed cut below the chin, about an inch and a half in length, and of irregular outline. The only other evidence of the injury was a complete internal rotation of the left eyeball. When the child looked fully to the left with the right eye, the left eye barely came to the middle of the palpebral fissure. Both pupils were equal in size and reacted normally to light. Both fundi were normal.

On September 9, under atropine, the refraction of both eyes was +2.0 D.Sph., and the child was ordered B.E. + 1.5 D.Sph. for constant use. No further abnormality than that already noticed was found.

The child was put on exercises, very gradually at first in view of the paresis of the left external rectus muscle, and return of function of the muscle has slowly progressed.

On January 29, 1930, the mother stated that the child's eye had recovered its " brightness," and that sometimes it looked quite straight, especially in the morning on waking. But, on each occasion that I have seen her, the eye has been internally rotated. Movement has returned to the extent that the edge of the left cornea can be rotated to the outer canthus. There is difficulty in making the child fix with the left eye, but she named several things correctly when they were held before the eye. Her fundi are still normal. 
Comment.- The persisting inward rotation of the eye appears to be due to stretching of the left external rectus muscle during the time that it was paralysed. And although the function appears to have fully recovered, the stretching has remained. In view of the surgical principle that paralysed muscles should be put at rest, it seems to me that the correct treatment in this case would have been to fix the eye with a suture in full outward rotation as soon as the paralysis was discovered. This would have prevented the stretching of the muscle. Unfortunately, I did not think of this until too late. But in any case, a fortnight after the accident was probably too long for any benefit to have resulted. The case, however, seems to point to the importance of early suture in a position of rest in cases of traumatic ocular paralysis.

\title{
A CASE OF BILATERAL BUPHTHALMIA WITH MULTIPLE CONGENITAL ABNORMALITIES IN ONE EYE
}

\author{
BY \\ G. G. PENMAN \\ LONDON
}

L. P., male, aged 6 years, attended at the Royal Westminster Ophthalmic Hospital on October 5, 1929. The parents said that for five years the child had had defective eyesight, and " would not look up."

Examination was extremely difficult on account of photophobia, but it was quite obvious that the condition was buphthalmia, in a very advanced state.

The child was admitted, and on October 9 was given a general anaesthetic and examined more thoroughly.

The right eye showed the ordinary features of an advanced case of buphthalmia; the cornea very large, steamy, and with many splits in Descemet's membrane, a very deep anterior chamber; fundus not visible. Tension, by Schiötz tonometer, $37 \mathrm{~mm}$. $\mathrm{Hg}$.

In the left eye, besides these features, there was almost complete aniridia, the rim of rudimentary iris showing as a dark brown border, except at about 11 o'clock, where there appeared to be a wider iris, from the anterior surface of which a strip of white anterior vascular sheath remnant, with some vessels on its surface, ran to the centre of the anterior surface of the lens. The edge of the lens presented below a double coloboma, the suspensory ligament being absent in that region. Tension was $30 \mathrm{~mm}$. $\mathrm{Hg}$. later.

The left eye was trephined the same day, and the right a week 